\title{
Representation of New Electrical Load Tariff to Be Implemented in Future
}

\author{
Harshita Thadesar \\ (Electrical, G.H.R.C.E.M AMRAVATI/ SGBAU AMRAVATI, INDIA)
}

\begin{abstract}
The demand for electricity in India is increasing every day. As per demand utility is required to generate, transmit and distribute electricity among different consumers. The cost incurred by utility for this purpose is recovered from different consumers by applying a suitable tariff. Load curve of Indian utility is peaky in morning and evening hours. Naturally, cost of generation will also increase in order to meet the peak demand. To reduce this gap it is necessary to shift the load of certain consumer categories to off peak hours. The major load on utility system is industrial, and hence if industries would take initiatives for flattening the load curve by shifting their loads from peak hours to off peak load hours, it will profitable to both utility and industry. Design of load tariff structure for industrial consumers encourages consumers to shift their energy usage. Under load tariff, consumption during different hours of the day is charged differently. The paper investigate the concept, implementation and impact of load tariff and other tariff based incentives/disincentives.

Keywords: Availability based tariff(ABT), General tariff system, Load tariff, Tariff of electricity .
\end{abstract}

\section{Introduction}

Now a day's our need is to have electrical power with maximum efficiency and in less cost. Our power consumption is increasing day by day for domestic, industrial and commercial purpose and in turn energy cost is also increasing. The cost incurred by utility for this purpose is recovered from different consumers by applying a suitable tariff. Hence, a topic is dissertation work which relates to reduction in energy cost. The main motto is to minimize the power consumption and in turn reduce the energy bill of customer by utilizing electrical load during off peak load hours by way of effective management of the load. My intension behind this paper is to suggest electric power supply companies in turn to government to propose new tariff system for the electric supply users which may be named as Off-Peak Load Tariff System. The paper presented by Sanjeev S. Ahluwalia , Tariff setting is a primary instrument of economic regulation. Tariff provides economic signals, which determine the volume and nature of demand and supply. It is not surprising therefore that a considerable portion of the reform effort is expended on rationalizing tariffs, often disproportionately sol. It is attractive to assume that the financial viability of the distribution business can be improved merely through technical corrections to the design and the level of tariff. The experience shows otherwise. Regulatory Commissions have been constrained from more efficient tariff setting due to the non responsiveness of public utilities to economic signals, continued poor quality, high cost and inefficiency of supply. Tariff reform can improve allocative efficiency by providing better price signals [2]. It can increase the revenue inflow in those consumer classes where costs are currently under recovered. Distribution companies provide electricity at different rates to different categories of consumers. Every state has different categories that cater to the needs of the businesses prevalent in their states. But the most common categories are domestic (residential), commercial (shops and offices) and Industrial (manufacturing units). With rates being lowest for residential consumers and highest for industrial consumers. Within these categories there are separate rates for low tension and high tension. Many times the categories are also differentiated depending on the connected load and the tariffs increase if the connected load is higher. While cost of generation, transmission and distribution are the same, but the tariffs charged for different consumers is different. For example, if the average cost of service is Rs. 3/unit, the domestic consumer may be charged at Rs 2.5/unit while an industrial consumer may be charged at Rs 3.5/unit. In this case, it is said that the domestic consumers are cross-subsidized by industrial consumers. These cross subsidies have been put in place in the country to make sure that the common man is not burdened much with the rising electricity costs. Industries and business take the most burdens of higher electricity costs. And thus the tariffs are different for different categories of consumers. In our India we are using general tariff system and we have to pay same rate for units for $24 \mathrm{hrs}$. But in foreign countries they are using two tariff system so on the basis of peak load time and off peak load time they pay the different charges and they save the power consumption and minimize the bill rate. So, the efforts are made in this project to utilize the power during off peak load hours. The peak load hours and off peak load hours are already declared by the power supply companies. From time verses current graph, it is easy to know when and at which time the power is to be utilized so as to reduce the energy bill. For the execution, we are using MATLAB, X-CTU and Flash-magic software. 


\section{General Tariff System:-}

\section{Methodology}

Tariff refers to the amount of money, the consumer has to pay for making the power available to them at their homes. Tariff system takes into account various factors to calculate the total cost of the electricity. Before understanding tariff of electricity system in detail a slight overview of the entire power system structure and hierarchy in India would be very fruitful. The electrical power system mainly consists of generation, transmission and distribution. For generation of electrical power we have many PSUs and private owned generating stations (GS). The electrical transmission system is mainly carried out by central government body PGCIL (Power grid corporation of India limited). To facilitate this process, India is divided into 5 regions Northern, Southern, Eastern, Western and North eastern region. Further within every state we have a SLDC (state load dispatch centre).The distribution system is carried out by many distribution companies (DISCOMS) and SEBs (State electricity board).

\subsection{Type :-}

At present tariff system is one for the consumer which they pay to the DISCOMS and other which they pay to the Generating Stations. Let us first discuss about the tariff of electricity for the consumer that is the cost consumer pay to the DISCOMS. The total cost levied on the consumer is divided into 3 parts usually referred as 3 part tariff system.

Total cost of electrical energy $=$ fixed cost + semi fixed cost + variable cost

$$
=(\mathrm{a}+\mathrm{b} * \mathrm{KW}+\mathrm{c} * \mathrm{KW}-\mathrm{h}) \mathrm{Rs} \text {. }
$$

Here, $\mathrm{a}=$ fixed cost independent of the maximum demand and actually energy consumed. This cost takes into account the cost of land, labor, interest on capital cost, depreciation etc.

$\mathrm{b}=$ constant which when multiplied by maximum KW demand gives the semi fixed cost. This takes into account the size of power plant as maximum demand determines the size of power plant.

$\mathrm{c}=\mathrm{a}$ constant which when multiplied by actual energy consumed KW-h gives the running cost. This takes into account the cost of fuel consumed in producing power. Thus the total amount paid by the consumer depends on its maximum demand, actual energy consumed plus some constant sum of money. Now electrical energy is generally expressed in terms of unit, and 1 unit $=1 \mathrm{KW}-\mathrm{hr}(1 \mathrm{KW}$ of power consumed for $1 \mathrm{hr})$.

All these costs are calculated on active power consumed. It is mandatory for the consumer to maintain a power factor of 0.8 or above otherwise penalty is levied on them depending on the deviation. Let us now discuss about the tariff system existent in India for the DISCOMS. It is regulated by CERC (central electricity regulatory commission). This tariff system is called availability based tariff (ABT). As its name suggest it is a tariff system which depends on the availability of power. It is a frequency based tariff mechanism which tends to make the power system more stable and reliable. This tariff mechanism also has of 3 parts: Fixed charge + capacity charge + UI (Unscheduled interchange). The fixed charge is same as that discussed above. The capacity charge is for making the power available to them and depends on the capacity of plant and the third one is UI. To understand the UI charges let us see the mechanism.

\subsection{Mechanism of ABT:-}

- The generating stations commit a day ahead about the schedule power which they can provide to the regional load dispatch centre (RLDC). The RLDC conveys this information to various SLDC which in turn collects the information from various state DISCOMS about the load demand from various types of consumers.

- The SLDC sends load demand to RLDC. And now RLDC allocates the power accordingly to the various states. If every things goes well, power demand is equal to power supplied and the system is stable and frequency is $50 \mathrm{~Hz}$. But practically this rarely happens. One or more state overdraws or one or more GS under supplies. This led to deviation in frequency and system stability. If demand is more than supply frequency dips from normal and vice verse.

- UI charges are incentive provided or penalties imposed on the generating stations. If the frequency is less than $50 \mathrm{~Hz}$, implies demand is more than supply, then the GS which supplies more power to the system than committed is given incentives. On the other hand, if frequency is above $50 \mathrm{~Hz}$, implying supply is more than demand, incentives are provided to GS for backing up the generating power. Hence it tries to maintains the system stable.

\subsection{Time of day:-}

Usually during day period the demand for power is very high and the supply remains the same. Consumers are discouraged to use excess power by making the cost high. Contrary to that during night time, demand is less compared to supply and hence consumers are encouraged to use power by providing it at cheaper rate. All these are done to make/keep the power system stable. 


\section{Load Tariff System:-}

As per the general tariff system, we have to pay same charges for all 24 hours on the utilized electrical power. It will get costly to consumers. So for the benefit of costumer we are proposing a new load tariff system. In proposed load tariff system, consumer can do the analysis of the power consumed by him every month. Because distribution company can provide the graph of load utilized by him during all the 24 hours of the day along with the energy bill. From the graph he will come to know that the maximum power is to be utilized. If the off peak load tariff the rates of power consumption during off peak load is less than of peak load hours. However, the peak load and off peak load hours are already declared by electricity supply companies.

\section{Block Diagram}

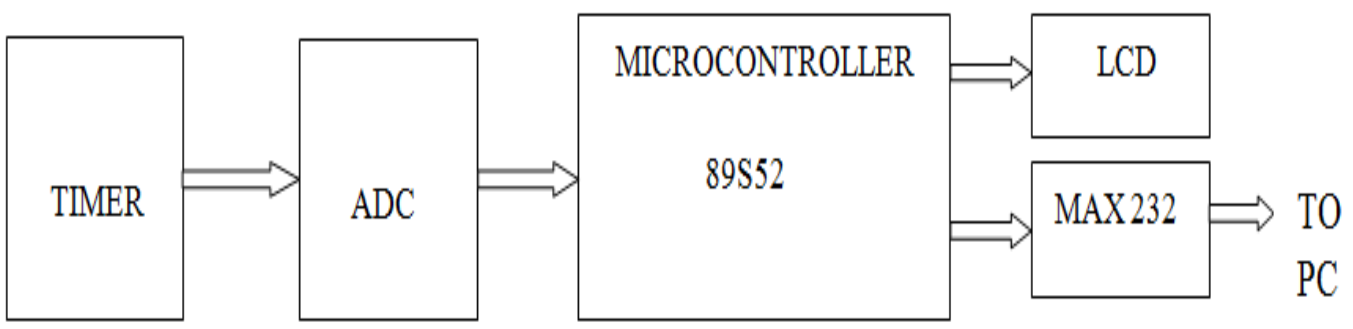

Fig: 1 Block diagram

Above block diagram shows step by step procedure to get desired result on computer. In this we have to show the representation of graph on the software called as MATLAB in which we have already set the program. So there are step by step procedure by which we can get the graph and from graph further analysis is done. Initially the main switch is made on and then USB to serial port is connected to computer. Then we check that whether this port is initialize or not. For that we are using X-CTU software. X-CTU is a software which is use to check whether com is detected or not. There are other software also use to check whether this USB to serial port is initialize or not that is Prolific 2303 serial port, $\mathrm{C}$ code for teensy. After initialization of USB to serial port we can switch on the supply. As soon as the supply is switched on then the value of voltage is displayed on 16x2 LCD display which is connected to the micro controller chip.There is load bank present on the kit on which various loads are connected in parallel. The loads are connected in parallel because to supply same voltage to every equipment. As we made load on the readings are observed in the software called as Flash Magic. Flash magic is use to copy the values in MATLAB. In flash magic the values of current are observed. Now this values from flash magic are copied and then paste in the MATLAB program. The MATLAB program which we are using is as shown below.

clear all

clc

format short

$\mathrm{s}=$ serial('COM1', 'BaudRate', 9600);

fopen(s)

$\mathrm{abc}=0$;

for $\mathrm{i}=1: 5$

fprintf(s,'*IDN?')

$\operatorname{arrr}=$ fscanf $\left(\mathrm{s}, ' \% \mathrm{f}^{\prime}\right)$

$\operatorname{abc}(\mathrm{i})=$ arrr;

end

$\operatorname{plot}\left(\mathrm{abc}, \mathrm{r}^{*-'}\right)$

fclose(s)

delete(s)

clear( s)

In this above program paste the occurred readings in flash magic software. Microcontroller is the most important chip in this overall project. We are using 89S5 microcontroller for our circuit. As we know microcontroller is embedded system which has various pins. Through this pin various components are connected. Initially current is supplied through CT. Then this is pass to ADC. Now as the input is sinusoidal i.e. in the AC form, therefore it is necessary to convert it into DC. For that purpose ADC chip is used, and this ADC is connected to microcontroller 89S52.Now values from the flash magic which we have copied and paste in the MATLAB program. Then it is necessary to set the com specification. After it is saved and run the graph time and consumed load will be displayed. 


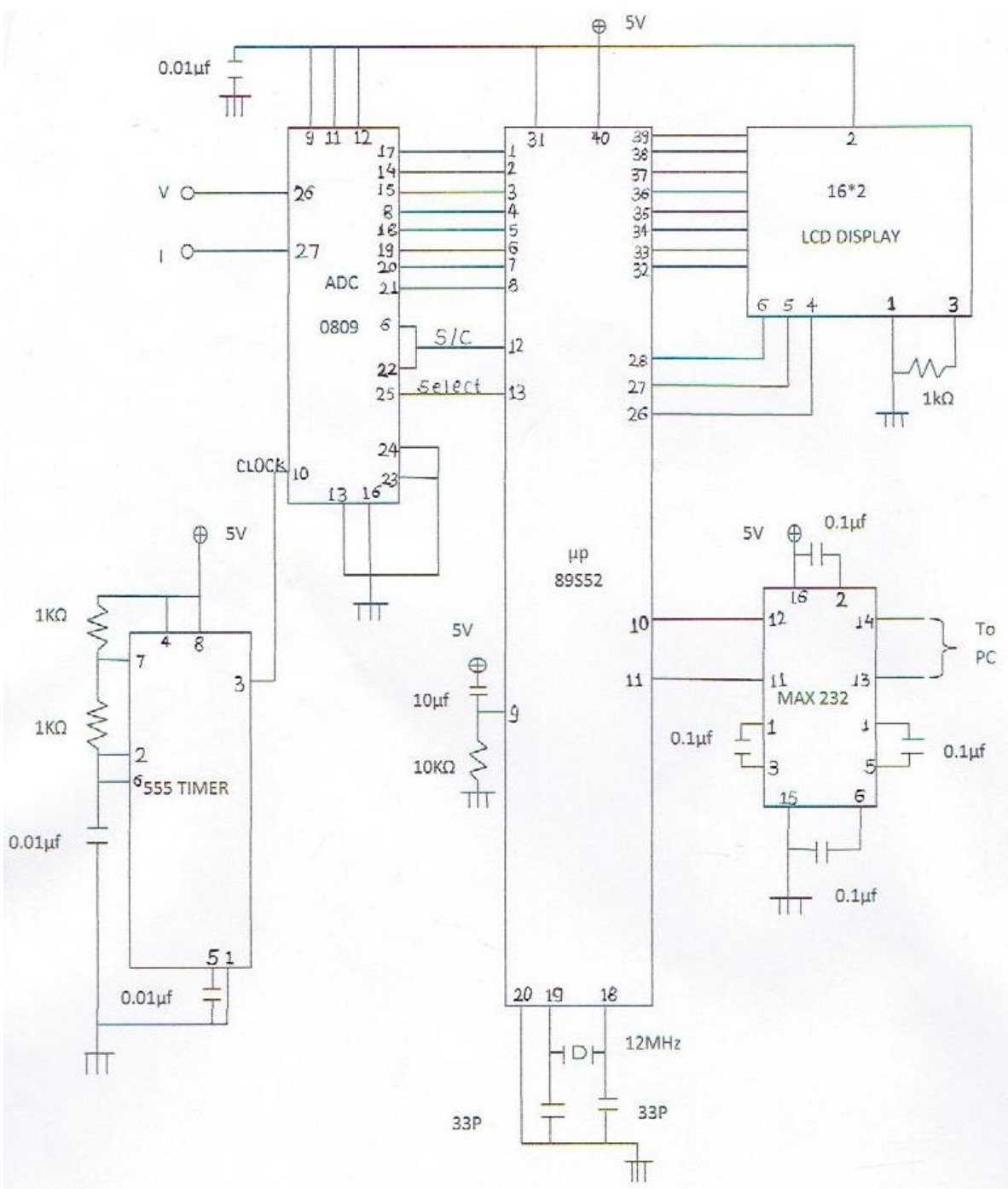

Fig: 2 Circuit diagram

Above circuit diagram shows the connection of components which used to make our circuitry.

\section{Result Analysis}

After the execution of the project the graph between load and time is displayed on the MATLAB as shown below:

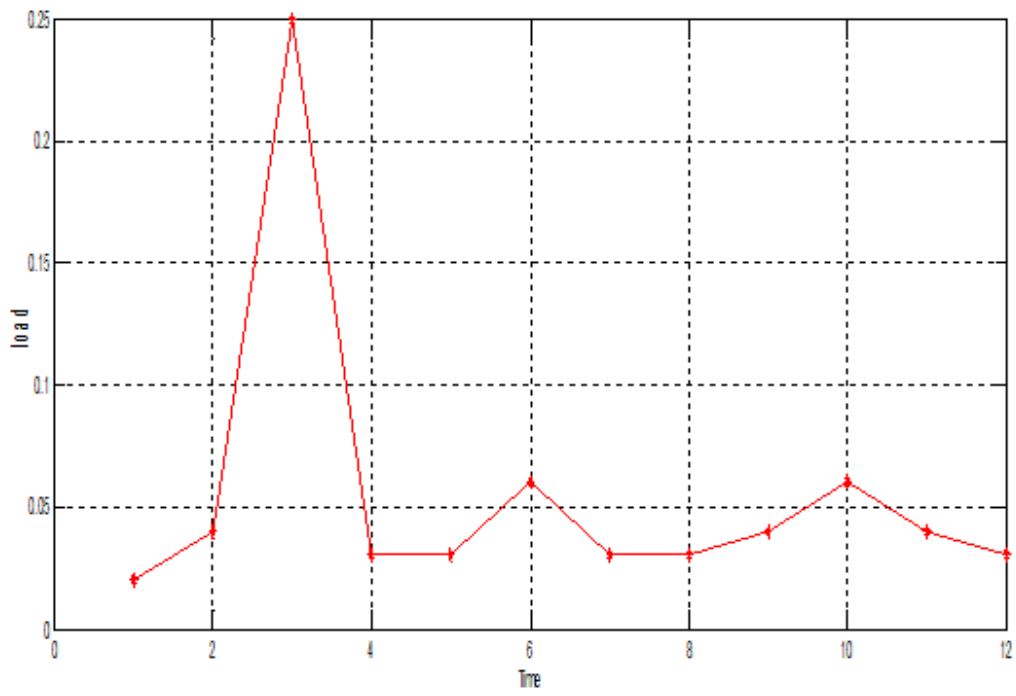

Fig: 3 Time- load characteristic 
From the above graph it is observed that $0.25 \mathrm{~A}$ is the peak value of current at $3 \mathrm{Hrs}$ (say). However for the sake of convenience graph is plotted between load in Amperes and time in seconds. It means that at $3 \mathrm{Hrs}$ the maximum load is used. No doubt for residential consumers 3 Hrs is off peak hours. That means, naturally as per the billing technique to be introduced in future, the energy bill shall definitely be on lesser side than if it is used at peak load hours say from 5-8 am and 6-10 pm.

The peak load hours and off peak load hors are universally defined. As per present practice in Maharashtra, peak load hours are from $5 \mathrm{Am}$ to $8 \mathrm{Am}$ and from $6 \mathrm{Pm}$ to $10 \mathrm{pm}$. The remaining are the off peak load hours. Some calculation of peak load value and off peak load values are shown in observation table.

Table: Observation table

\begin{tabular}{|l|l|l|l|l|l|}
\hline Sr. no & $\begin{array}{l}\text { Load utilized } \\
\text { in amp }\end{array}$ & $\begin{array}{l}\text { Time for which load } \\
\text { is utilized }\end{array}$ & Voltage & $\begin{array}{l}\text { Power consumption } \\
\text { in VAh }\end{array}$ & $\begin{array}{l}\text { Power consumption } \\
\text { in KWh }\end{array}$ \\
\hline 1 & 0.25 & $3 \mathrm{sec}$ & 230 & 2.875 & 0.00287 \\
\hline 2 & 0.06 & $6 \mathrm{sec}$ & 230 & 1.38 & 0.00138 \\
\hline 3 & 0.025 & $10 \mathrm{sec}$ & 230 & 0.958 & 0.000958 \\
\hline
\end{tabular}

Calculation:-

$$
\begin{aligned}
\mathrm{P} & =\mathrm{V} * \mathrm{I} * \mathrm{~T} / 60 \\
& =230 * 0.25 * 3 / 60 \\
& =2.87 \mathrm{VAh} \\
& =2.87 / 1000 \\
& =0.00287 \mathrm{KWh}
\end{aligned}
$$

Overall Result:-

- After execution, graph between time and load is displayed as shown in fig; on $\mathrm{x}$-axis there is time while $\mathrm{y}$ axis represent load.

- This graph will show that at what time the maximum load is consumed.

- $\quad$ From the graph we can calculate the power consumption in KWh.

\section{Conclusion}

At present our nation is facing energy crisis and hence this scheme can be beneficial for the increase so called generation capacity because it is always presumed that lunit of power saved is 1.5 units of energy generated. From the graph/observation table it is concluded that if the power is utilized at off peak load hours, naturally the consumption will be less and in turn the energy bill will also be less. From the above discussion we can also conclude that, If the new load tariff is introduced then the consumer shall naturally utilize power/energy during off peak load hours so that reduction in energy bill/consumption can be achieved and naturally the energy conservation can naturally be observed.

\section{References}

[1]. H. Saele, J. A. Foosaes, V. Kristoffersen, T. E. Nordal, O. S. Grande, and B. A. Bremdal, "Network Tariffs and Energy Contracts with Incentives for Demand Response, " presented at the CIRED Workshop, Paper no. 0314, Rome, 2014.

[2]. Sanjeev S. Ahluwalia, "Tariff Setting in the Electric Power Sector Base paper on Indian Case Study, " vol.4, No. 512-518, 2009.

[3]. P.Vijayapriya, "Smart Tariff for Smart Meters In Smart Grid," International Journal of Engineering and Technology Vol. 2, No. $310-315,2010$

[4]. B. N. Goldar and H. N. Saleem, "India's Tariff Structure: Effective Rates of Protection of Indian Industries," Studies in Industrial Development, Ministry of Industry, Government of India, Paper No. 5, October 1992.

[5]. $\quad$ A. Bishop, “Tariff Development II: Rate Design," National Association of Regulatory Utility Commissioners Energy Regulatory Partnership Program, 2008. 